\title{
Strong migratory connectivity across meta-populations of sympatric North Atlantic seabirds
}

\author{
Benjamin Merkel ${ }^{1,2,15, *}$, Sébastien Descamps ${ }^{1}$, Nigel G. Yoccoz ${ }^{2}$, David Grémillet ${ }^{3,4}$, \\ Per Fauchald ${ }^{5}$, Jóhannis Danielsen ${ }^{6}$, Francis Daunt ${ }^{7}$, Kjell Einar Erikstad ${ }^{5,8}$, Aleksey V. \\ Ezhov $^{9}$, Mike P. Harris ${ }^{7}$, Maria Gavrilo ${ }^{10,11}$, Svein-Håkon Lorentsen ${ }^{12}$, Tone K. Reiertsen ${ }^{5}$, \\ Geir H. Systad ${ }^{13}$, Thorkell Lindberg Thórarinsson ${ }^{14}$, Sarah Wanless ${ }^{7}$, Hallvard Strøm ${ }^{1}$ \\ ${ }^{1}$ Norwegian Polar Institute, Fram Centre, PO Box 6606 Langnes, 9296 Tromsø, Norway \\ ${ }^{2}$ Department of Arctic and Marine Biology, University of Tromsø-The Arctic University of Norway, 9037 Tromsø, Norway \\ ${ }^{3}$ Centre d'Ecologie Fonctionnelle et Evolutive, UMR 5175, CNRS - Université de Montpellier-Université Paul-Valéry \\ Montpellier-EPHE, Montpellier, France \\ ${ }^{4}$ FitzPatrick Institute, DST-NRF Centre of Excellence at the University of Cape Town, Rondebosch 7701, South Africa \\ ${ }^{5}$ Norwegian Institute for Nature Research, Fram Centre, PO Box 6606 Langnes, 9296 Tromsø, Norway \\ ${ }^{6}$ University of the Faroe Islands, Vestarabryggja 15, 100 Tórshavn, Faroe Islands \\ ${ }^{7}$ Centre for Ecology \& Hydrology, Bush Estate, Penicuik, Midlothian EH26 0QB, UK \\ ${ }^{8}$ Centre for Biodiversity Dynamics, Department of Biology, Norwegian University of Science and Technology, 7491 Trondheim, Norway \\ ${ }^{9}$ Murmansk Marine Biological Institute, 17 Vladimirskaya Street, 183010 Murmansk, Russia \\ ${ }^{10}$ Association Maritime Heritage, 199106, Icebreaker "Krassin", The Lieutenant Schmidt emb., 23 Line, Saint Petersburg, Russia \\ ${ }^{11}$ National Park Russian Arctic, 168000, Sovetskikh Kosmonavtov Ave. 57, Archangelsk, Russia \\ ${ }^{12}$ Norwegian Institute for Nature Research, PO Box 5685 Sluppen, 7485 Trondheim, Norway \\ ${ }^{13}$ Norwegian Institute for Nature Research, Thormøhlensgate 55, 5006 Bergen, Norway \\ ${ }^{14}$ Northeast Iceland Nature Research Centre, Hafnarstétt 3, 640 Húsavík, Iceland \\ ${ }^{15}$ Present address: Akvaplan-niva, Fram Centre, PO Box 6606 Langnes, 9296 Tromsø, Norway
}

\begin{abstract}
Identifying drivers of population trends in migratory species is difficult, as they can face many stressors while moving through different areas and environments during the annual cycle. To understand the potential of migrants to adjust to perturbations, it is critical to study the connection of different areas used by different populations during the annual cycle (i.e. migratory connectivity). Using a large-scale tracking data set of 662 individual seabirds from 2 sympatric auk meta-populations (common guillemots Uria aalge and Brünnich's guillemots U. lomvia) breeding in 12 colonies throughout the Northeast Atlantic, we estimated migratory connectivity in seasonal space use as well as occupied environmental niches. We found strong migratory connectivity, within and between species. This was apparent through a combination of seasonal space use and occupied environmental niches. Brünnich's guillemot populations grouped into 2 and common guillemot populations into 5 previously undescribed spatiotemporal clusters. Common guillemot populations clustered in accordance with the variable population trends exhibited by the species, while Brünnich's guillemot populations are declining everywhere where known within the study area. Individuals from different breeding populations in both species were clustered in their space and environmental use, utilising only a fraction of the potential species-wide range. Further, space use varied among seasons, emphasising the variable constraints faced by both species during the different stages of their annual cycle. Our study highlights that considering spatiotemporal dynamics, not only in space but also in occupied environmental niches, improves our understanding of migratory connectivity and thus population vulnerability in the context of global change.
\end{abstract}

KEY WORDS: Environmental niche $\cdot$ Inter-population mixing $\cdot$ Large-scale spatiotemporal dynamics $\cdot$ Light-level geolocation $\cdot$ Murres $\cdot$ Population spread $\cdot$ Seasonality

${ }^{*}$ Corresponding author: merkel.scholar@gmail.com

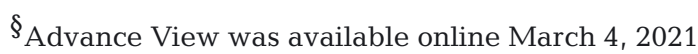

() The authors 2021. Open Access under Creative Commons by Attribution Licence. Use, distribution and reproduction are unrestricted. Authors and original publication must be credited.

Publisher: Inter-Research · www.int-res.com 


\section{INTRODUCTION}

Migratory animals face specific challenges in a rapidly changing world, such as loss of habitat, new physical barriers, overexploitation of seasonal food resources and climate change impacts (Wilcove \& Wikelski 2008, Robinson et al. 2009). Changes in the environment encountered by migrants outside their breeding season have the potential to affect population trends through, for example, an effect on individual survival (Webster et al. 2002, Gaston \& Powell 2003). Hence, assessing the response of migratory species or populations to perturbations requires an understanding of migratory connectivity (Taylor \& Norris 2010), which is the connection of different areas used by different populations during the annual cycle. It is typically described along a continuum from low (also termed weak, or diffuse) to high (or strong) (Webster et al. 2002). Strong migratory connectivity (i.e. population-specific non-breeding areas) is necessary for differential population trends of geographically distinct breeding populations to be driven by factors away from the breeding sites (Kramer et al. 2018). Another aspect of migratory connectivity is population spread, which refers to the size of the geographic area occupied by a population during different parts of the annual cycle (Finch et al. 2017). Populations with smaller geographic spread have a limited variety of migratory movements and destinations and may thus be more vulnerable to perturbations than those with larger spread (Cresswell 2014, Gilroy et al. 2016).

The concept of migratory connectivity has so far focused on the geographic distribution of migrants but can be expanded to include their environmental niches. The niches used during the annual cycle can vary independently of the geographic area occupied as migrants move simultaneously in geographic space and among environmental conditions (Soberón 2007, Soberón \& Nakamura 2009, Peters et al. 2017). Consequently, migrants moving in similar geographic space may potentially occupy different environmental niches and vice versa (Gómez et al. 2016, Peters et al. 2017). Populations utilising many different environments are more likely to persist than those remaining within similar environments regardless of the occupied geographic area (Davies et al. 2004, Thuiller et al. 2005, Lavergne et al. 2013). Consequently, whether migratory connectivity is expressed in terms of space use or realized environmental niche (or both), it may have different consequences for the trajectories of the species. Moreover, in addition to the spatial and environmen- tal aspects of migratory connectivity it is also important to consider its seasonal dynamics, i.e. not only which sites and environments are used, but also when they are used. This can have manifold consequences on individual fitness (e.g. through transmission of pathogens) and therefore population dynamics (Bauer et al. 2016, Eyres et al. 2017, La Sorte et al. 2018).

Migratory connectivity is increasingly being studied in different taxa (Rooker et al. 2008, Godley et al. 2010, Frederiksen et al. 2012, 2016, Russell et al. 2013, Fayet et al. 2017) with a main focus on terrestrial birds (reviewed in Hahn et al. 2013, Taylor \& Stutchbury 2016, Finch et al. 2017, Kramer et al. 2018), where migratory connectivity is variable but often weak (Finch et al. 2017). Here, we assessed year-round spatial and environmental migratory connectivity within and between 2 sympatric circumpolar seabird species, the temperate common guillemot (hereafter COGU, Uria aalge) and the Arctic Brünnich's guillemot (hereafter BRGU, U. lomvia). These 2 auk species share similar morphology and life history (Gaston \& Jones 1998, Benowitz-Fredericks \& Kitaysky 2005). Their energetic costs for flight are among the highest recorded for any vertebrate (Elliott et al. 2013), suggesting severe constraints upon large-scale movement capabilities and high sensitivity towards habitat loss (Taylor \& Norris 2010). Guillemots also exhibit contrasting population trends in the Atlantic, with colonies of BRGUs generally declining within the Northeast Atlantic and those of COGUs exhibiting more variable trends (see Table 1) (Frederiksen 2010, Fauchald et al. 2015, Frederiksen et al. 2016, JNCC 2016, Anker-Nilssen et al. 2017, Garðarsson et al. 2019). Some evidence exists that population trends as well as adult survival in Uria spp. are associated with environmental conditions experienced during the non-breeding period (Gaston \& Powell 2003, Descamps et al. 2013, Mesquita et al. 2015, Fluhr et al. 2017) and that Atlantic-wide BRGU population trends are connected to mid-winter space use (Frederiksen et al. 2016).

Divergent population trends for these congeneric seabirds make them an ideal study system to investigate the importance of space and environmental connectivity across the migratory phase (Webster et al. 2002, Taylor \& Norris 2010, Gilroy et al. 2016). To characterise migratory connectivity and the potential link to population trends in Uria spp., we tracked the annual movements of 327 adult COGUs and 335 adult BRGUs from 12 breeding populations, representing almost the entire breeding range of the Northeast At- 
lantic population. To evaluate migratory connectivity in terms of inter-population mixing and population spread, within and across species, we not only considered the geographic areas occupied, but also the environmental conditions experienced and their variability during different phases of the annual cycle.

\section{MATERIALS AND METHODS}

\subsection{Study species and area}

Guillemots are large $(\sim 1 \mathrm{~kg})$, deep-diving (up to $\sim 200 \mathrm{~m}$ ), long-lived colonial seabirds with high adult survival, high breeding philopatry, high breeding synchrony and low annual fecundity (Gaston \& Jones 1998, Benowitz-Fredericks \& Kitaysky 2005). Their non-breeding period can be divided into several seasons corresponding to different life history stages throughout the annual cycle. Post-breeding, successful males stay with their flightless chicks for at least 1 mo after colony departure (Harris \& Wanless 1990, Elliott et al. 2017). Further, guillemots undergo moulting of their primaries and secondaries during 1-2 mo in the autumn post-breeding period which renders them flightless during this time period (Birkhead \& Taylor 1977, Thompson et al. 1998, Bridge 2004, Elliott \& Gaston 2014). Both species display periodic synchronized attendances at their breeding colonies starting up to several months prior to egglaying (Merkel et al. 2019), which in effect restricts them to central place foraging during this period. Hence, adult guillemots are only able to move without constraints for extended periods of time after they have renewed their flight feathers and before the pre-laying colony attendance period starts.

Research was conducted at 16 seabird colonies spanning $56-80^{\circ} \mathrm{N}$ and $16^{\circ} \mathrm{W}$ to $68^{\circ} \mathrm{E}$ in the Northeast Atlantic (see Table 1, Fig. 1A). For the purpose of this study, we combined some colonies in close spatial proximity to each other $(<160 \mathrm{~km})$ due to small sample sizes and observed similar space use patterns at some of these colonies as well as uncertainty connected to the tracking method used (see below). This resulted in 12 breeding populations. BRGUs and COGUs breed sympatrically at 4 of these sites (see Table 1).

\subsection{Tracking data}

We used archival light-level loggers to estimate spatiotemporal locations of guillemot individuals throughout the non-breeding period. These devices record light intensity and time, which can be used to estimate approximate latitude (i.e. day length) and longitude (i.e. time of noon) positioning twice daily. Their accuracy and precision varies over time and as a function of latitude, weather and habitat (estimated median accuracy: 180 km; Merkel et al. 2016). They are attached to a leg band with cable ties (logger, band and cable ties $<0.5 \%$ adult body mass) and need to be retrieved in subsequent years after deployment for data to be downloaded. During the summers of 2007-2017, we captured adult guillemots with noose poles at different sites and equipped them with geolocators which we retrieved in subsequent years (overall retrieval rate $>60 \%$ ). Individuals were chosen opportunistically in most cases among birds breeding on cliff ledges on the landward edge of the colony. This resulted in 1103 annual tracks (531 BRGUs, 572 COGUs) of 662 individual guillemots (335 BRGUs, 327 COGUs; see Table 1). All subsequent analyses were conducted in $\mathrm{R}$ v.3.3.3 ( $\mathrm{R}$ Development Core Team 2017). All loggers (Mk15: British Antarctic Survey; Mk3006: Biotrack; F100, C250 and C330: Migrate Technology; or L250A: Lotek) also recorded temperature and salt water immersion ('wet/dry') data which were used in combination with recorded light data to increase location accuracy. We calculated a most probable movement track for each individual and tracking year using an iterative approach utilising probability sampling (Merkel et al. 2016 and details in Supplement 1 at www.int-res.com/articles/suppl/m676p173_supp/). We binned the positional data into 4 seasons to capture possible variability due to life history stages throughout the annual cycle. This was done irrespective of year tracked, as a recent study showed individual consistency in non-breeding movements across years (Merkel et al. 2020). The seasonal delimitation was based on assessments of core time periods in which little movement was observed across all individuals from all colonies and both species, resulting in autumn (10 August-28 September), early winter (18 November-6 January), late winter (17 January-25 February) and spring (27 March-25 May). We assume that autumn describes the post-breedingmoulting period, the 2 winter seasons capture temporal variability in movement behaviour during times without movement restrictions for most breeding populations, and spring is characterised by central place foraging restrictions due to pre-laying attendance at most colonies. Although sample size in some populations was potentially not sufficient to capture their entire distributional range (see Table 1), it 
nonetheless was adequate to represent the potential variability of exhibited migration strategies.

\subsection{Environmental niche}

To quantify environmental niches occupied during the non-breeding period, we used 8 ecologically relevant oceanographic parameters (Fort et al. 2009, 2013b, McFarlane Tranquilla et al. 2015); 3 sea surface temperature variables, 2 sea surface height variables, surface air temperature, distance to the marginal sea ice zone and bathymetry (details in Supplement 1). The environment occupied was then assessed using the concept of environmental space (Broennimann et al. 2012) defined as the first 2 axes of a principal component analysis (PCA) of all environmental parameters calibrated on the available environment. To capture the variability of the available environment, we sampled 20000 random points across the entire study area (Fig. S1.2 in Supplement 1) every 2 wk for the entire study period (2007-2017). The study area was defined as the area encompassed by the 18 large marine ecoregions (hereafter ecoregions; Skjoldal \& Mundy 2013) intersecting with the annual distribution of both guillemot species in the Atlantic (Cramp 1985, Gaston \& Jones 1998) (see Fig. 1A). Ecoregions are large oceanic regions along coasts and continental shelfs characterised by specific ecological criteria (Skjoldal \& Mundy 2013). To accommodate the aforementioned distributions, 3 additional areas in the open ocean away from continental shelfs were defined (Labrador Sea, Mid-Atlantic and Central North Atlantic) using prior information on the species' distributions (Cramp 1985, Gaston \& Jones 1998). All individual bird positions were projected onto the PCA (PC1 $=44 \%, \mathrm{PC} 2=19 \%$; Fig. S1.3). Available and occupied environmental space were then calculated using Gaussian kernel utilisation distributions (UD; standard bandwidth, $200 \times 200$ pixel grid, 'adehabitatHR' package; Calenge 2006) following Broennimann et al. (2012).

\subsection{Estimating migratory connectivity}

Following Finch et al. (2017), we estimated migratory connectivity as inter-population mixing as well as population spread. We calculated inter-population mixing in geographic space on 2 scales - on large and meso scale - in order to be able to quantify migratory connectivity given the complex nonbreeding movements of these species and the track- ing method used. Further, we expanded the concept of migratory connectivity as inter-population mixing and population spread also in the environmental niches occupied by these species.

\subsubsection{Large-scale inter-population mixing}

To quantify inter-population mixing and specieswide spatiotemporal movement partitions across the North Atlantic, we developed species-specific movement networks using network theory (Taylor \& Norris 2010). All estimated bird positions were assigned to ecoregions. We then used the proportion of locations in each ecoregion in seasonal cluster analysis (complete-linkage clustering) to assign each individual to a given ecoregion. To avoid pseudo-replication, we used only 1 yr of tracking, randomly selected, for each individual with repeated tracks. The optimal number of clusters was determined using overall average silhouette width (Borcard et al. 2018) for each season. For individuals affected by midnight sun conditions during the spring season, we included the proportion of locations unavailable due to a lack of twilight events in the cluster analysis. Similarly, for the few instances where individuals during early winter had no locations due to polar night influence (i.e. a lack of twilight events; Table S1.2), birds were assumed to use the ecoregion 'Barents Sea' as this was only the case for individuals with breeding colonies in the Barents Sea. Each breeding population present in the network was given the same weight and considered to be a node in the network $\left(8\right.$ species $\left.^{-1}\right)$. Next, each individual in a given population got a proportional weight based on the total available tracks from that population. These scaled movements (network edges) between ecoregions and seasons (network nodes) were combined to create species-specific movement networks.

To identify possible partitioning within each species-specific network, we used a Walktrap community finding algorithm (finding clusters via random walks with 5 steps taking into account the proportional movement between ecoregions and seasons, 'igraph' package; Csardi \& Nepusz 2006). This method also returns a modularity index that ranges from $0-1$ (the closer to 1 , the more the network exhibits clustering with respect to the given node grouping). A network is considered to exhibit significant cluster structuring above a value of 0.3 (Clauset et al. 2004). Total number and proportional use of population- and species-specific most common migration strategies were identified as unique individual movement paths through each network. A high number of strategies 
and low proportion of individuals following the most common strategy would indicate weak migratory connectivity and vice versa. In addition, a species-wide Mantel correlation was used as an independent method to quantify migratory connectivity (Ambrosini et al. 2009, Cohen et al. 2018) and was computed for individual $10 \mathrm{~d}$ centroid locations throughout the nonbreeding period to assess the robustness of our results (details in Supplement 1).

\subsubsection{Meso-scale inter-population mixing}

To quantify if populations and species mix or segregate within ecoregions, we calculated individual seasonal kernel UDs in geographic space $(25 \mathrm{~km}$ grid resolution in polar stereographic projection and a bandwidth of 30 based on a median least square cross-validation score of all individual- and seasonspecific kernel UDs). The degree of mixing between populations and species in each ecoregion and season was then estimated as the average overlap as Bhattacharyya's affinity (Fieberg \& Kochanny 2005) between 4 random individual kernel UDs from the same population (intra-population) as well as the average overlap between 4 random individual kernel UDs of either population compared (2 individuals each; inter-population). This process was repeated 1000 times for both pairs in the comparison. If the intra-population overlap is significantly greater than the inter-population overlap (1-tailed $t$-test with Bonferroni corrected significance level, $p=0.05 /$ number of correlation tests) then space use is defined as population-specific within the ecoregion and season. We used this test for all populations of either species with at least 4 individuals present in the same ecoregion and season. The resulting comparisons were summed to species- (within and between species, $s p$ ) and cluster-specific (within and across clusters, $C$ ) proportions of inter-population mixing within ecoregions $(P)$ for each season $(t)$ ranging from 0 (populations segregate) to 1 (populations mix) using:

$$
P_{s p, c, t}=1-\frac{N_{\text {sim, } s p, c, t}}{N_{\text {all, } s p, c, t}}
$$

where $N$ is the number of considered comparisons, sim denotes only comparisons where intra-population overlap of either comparison pair is significantly greater than inter-population overlap and all denotes all comparisons. Ecoregion-, species- and seasonspecific Mantel correlations were calculated to assess the robustness of these results with an independent method (details in Supplement 1).

\subsubsection{Intra- and inter-population mixing of occupied environmental niches}

In order to quantify inter-population mixing of ecoregion-, species- and population-specific environmental niches occupied in each season, we used the niche similarity test by Warren et al. (2008). This test compares 2 occupied niches and addresses whether niche 1 is more similar to the compared niche 2 than would be expected by chance. The niche as kernel UD in environmental space of one comparison pair was randomly relocated within the available environmental space while retaining the UD's shape (1000 permutations for each comparison pair). Overlap between observed niches as well as the randomly relocated and observed niches was then calculated using Schoener's D (Broennimann et al. 2012). If the observed overlap is $>95 \%$ of the randomly relocated niches, the compared environments are considered to be more similar than expected by chance. We tested similarity between ecoregion-, species- and population-specific environmental spaces in each season to assess migratory connectivity in environmental space as well as niche partitioning between species. These environmental similarities together with the proportional use of different ecoregion by populations were then integrated into an environmental similarity index $(S)$. This index ranges from 0 (all birds occupy distinct environments) to 1 (all birds occupy a similar environment) and is computed for each $s p, c$ and $t$ as:

$\mathrm{S}_{s p, c, t}=\frac{\max \left(\mathrm{PR}_{s p, c, t, 1 \& 2}\right)^{2}+\sum_{\mathrm{sim}}\left(\mathrm{PR}_{s p, c, t, 1} \times \mathrm{PR}_{s p, c, t, 2)}\right.}{\max \left(\mathrm{PR}_{s p, c, t, 1 \& 2}\right)^{2}+\sum_{\text {all }}\left(\mathrm{PR}_{s p, c, t, 1} \times \mathrm{PR}_{s p, c, t, 2}\right)}$

where $P R$ is the proportional use of the compared nodes (1 and 2) and sim denotes only comparisons with similar environments (one way is considered sufficient, i.e. niche1 $\square$ niche2 $\square$ niche $2 \square$ niche1). As compared environmental spaces are population-, species- and in particular ecoregion-specific, we included a maximum term in Eq. (2) to account for the uneven distribution of a given population across ecoregions (Fig. S1.4). However, this term is not applicable, and hence removed, to compute the same index between populations and/or clusters ( $c 1$ and $c 2$ ) of the same species or between species ( $s p 1$ and $s p 2$; Fig. S1.4) resulting in:

$$
\mathrm{S}_{s p, c, t}=\frac{\sum_{\text {sim }}\left(\mathrm{PR}_{s p 1, c 1, t} \times \mathrm{PR}_{s p 2, c 2, t}\right)}{\sum_{\mathrm{all}}\left(\mathrm{PR}_{s p 1, c 1, t} \times \mathrm{PR}_{s p 2, c 2, t}\right)}
$$




\subsubsection{Population spread}

To quantify species and population spread in space and the environment, we calculated the occupied geographic and environmental space as the area covered by all relevant individual and seasonal $90 \%$ kernel UD contours in each season as well as the entire non-breeding period (all seasons combined).

\section{RESULTS}

\subsection{Large-scale inter-population mixing}

Both species exhibited marked spatial clustering on a large spatiotemporal scale with distinct annual migration strategies and strong migratory connectivity. Five and 2 distinct clusters (modularity of 0.59 and 0.36 indicating significant clustering) describing the non-breeding distribution were identified for COGUs and BRGUs, respectively (Table 1, Fig. 1B). These clusters were also visible in each season (Fig. 2, Supplement 2 at www.int-res.com/ articles/suppl/m676p173_supp/) and corresponded to their population trends (i.e. COGU populations whose individuals are part of the same cluster during the non-breeding season show the same trend; Table 1). For BRGU-declining all over our study area - a migratory divide was seen along the western Barents Sea edge splitting Spitsbergen BRGU populations (Fig. 2). Breeding populations to the west of this divide spent the autumn along eastern Greenland and moved towards Iceland and western Greenland during winter while birds breeding in the rest of the Barents Sea utilised the Barents and Kara Sea during autumn and generally stayed there year-round, except for Bjørnøya individuals (Fig. S3.13 in Supplement 3 at www.int-res.com/ articles/suppl/m676p173_supp/). Increasing COGU populations in the Barents Sea and decreasing populations in the Greenland and Icelandic Sea also grouped into these clusters, whereas populations in the Faroe Islands (decreasing trend), and the one along the coast of Norway (increasing trend) and eastern UK (increasing trend) displayed distinct migration strategies (Table 1, Figs. 1 \& 2). Both species exhibited little inter-population mixing between their identified clusters, with COGUs even less so than BRGUs (Table S1.4). An exception was visible for COGUs in the Barents Sea, where a varying proportion of birds from all breeding populations (except Iceland) congregated during autumn
(Figs. 1B \& 2). Species-wide Mantel correlation was also high $(>0.5)$ throughout the entire non-breeding period for both species (Fig. S1.5), confirming the identified strong migratory connectivity.

Each species utilised only a small fraction of potential migration strategies (indicating strong migratory connectivity), with BRGUs (60 unique strategies $=16 \%$ of possible paths through the network given the sample size) displaying more strategies than COGUs $(40=9 \%)$; both species combined only displayed 91 unique strategies $(11 \%)$ on this large spatiotemporal scale. At the breeding-population level, a variable but low amount of migration strategies were displayed with birds from the North-East and North Sea clusters showing little variability (Table 1). Most tracked individuals followed the most common population-specific strategy. Most variability in spatiotemporal use was visible for individuals in the Mid-West cluster, in particular for BRGUs (Table 1, Supplement 3).

\subsection{Meso-scale inter-population mixing}

Individuals from a given population and species were more likely to encounter conspecifics from their own population than an individual from a different population and/or species occupying the same ecoregion (Fig. 3). During autumn, BRGUs from all populations showed population-specific space use within ecoregions, while COGUs mixed to some extent (Figs. 1B \& 3). Most mixing was visible within species for individuals from the Mid-West cluster (around Greenland and Iceland). Here, principally during winter, individuals from different populations mixed within the same ecoregion. Most betweenspecies mixing was apparent during spring (Fig. 3), particularly for sympatrically breeding populations (Fig. S1.6). Ecoregion-specific Mantel correlation analysis corroborated these results (Fig. S1.5).

\subsection{Environmental intra- and inter-population mixing and species segregation}

Both species were composed of populations within clusters occupying distinct environments and hence exhibited little inter-population mixing in occupied environmental niches. Individuals from the same population and species occupied similar environments with most variability present during winter (Fig. 4). BRGU populations in the Mid-West clusterutilising a vast area — inhabited similar environments 


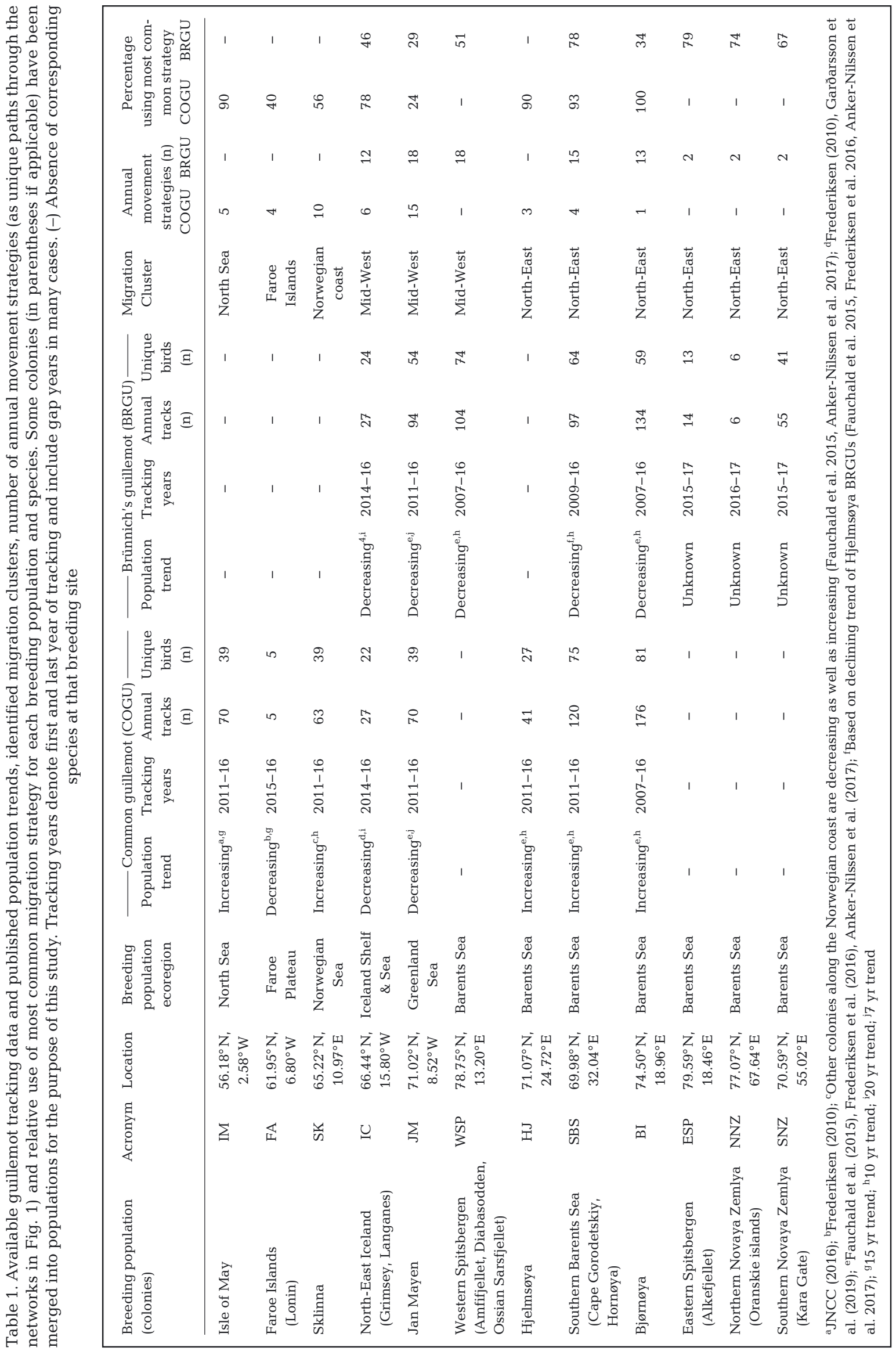


A
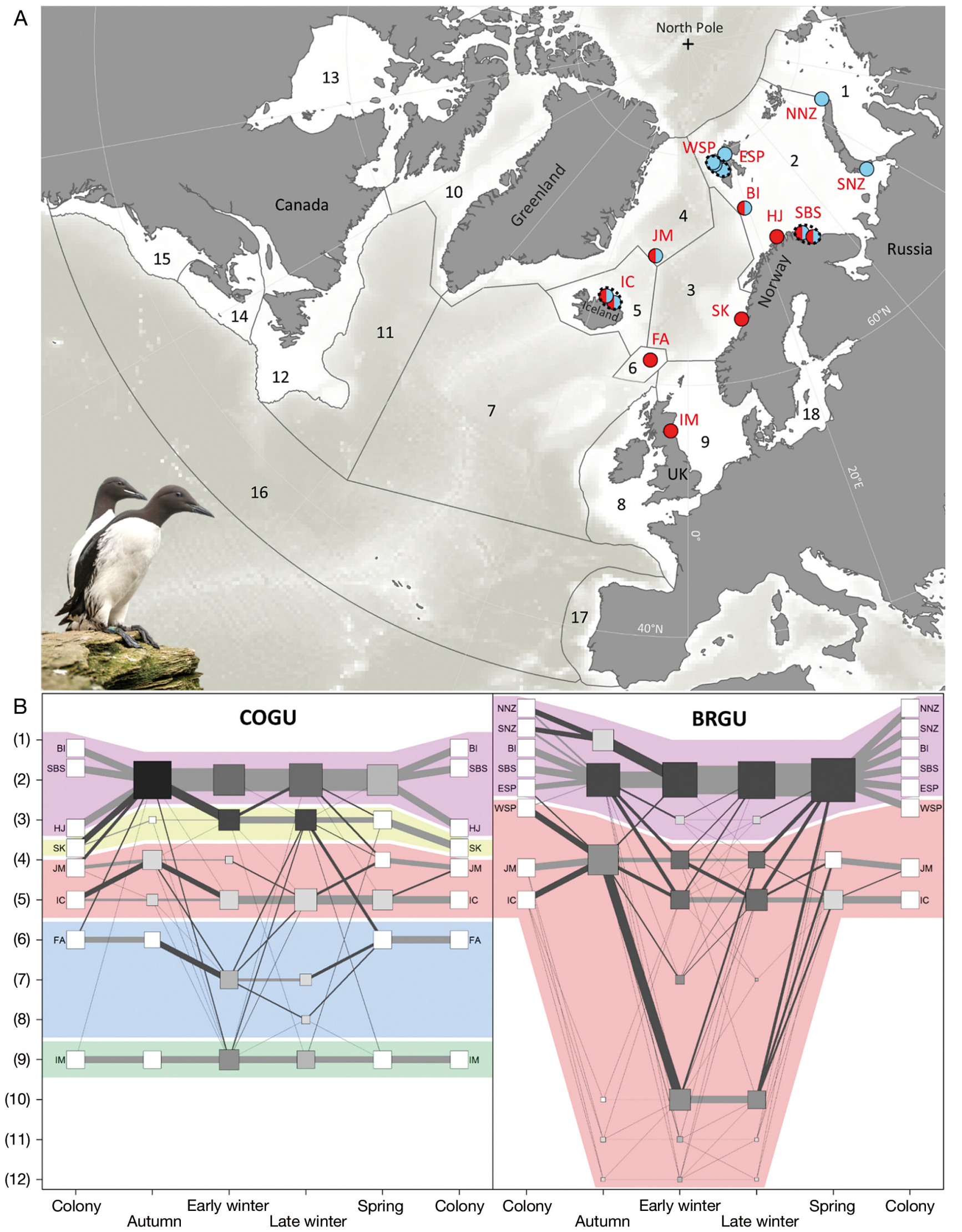
Fig. 1. (A) Study area (in polar stereographic projection) with bathymetry (Amante \& Eakins 2009, Jakobsson et al. 2012) and all large marine ecoregions included in the study (names detailed below). Circles: study colonies (red: common guillemot [COGU]; blue: Brünnich's guillemot [BRGU]). Colonies combined for the purpose of this study are encircled with dashed ellipsoids. (B) Movement networks for both species by ecoregion (numbering corresponds to [A]) and season. Each breeding population is scaled to the same size, while all nodes (squares) and edges (lines) are scaled to their proportional usage accordingly. Nodes are greyscale-coded by number of populations present from white (only individuals from one population present) to black (8 populations present). Coloured backgrounds display identified clusters (5 for COGU; 2 for BRGU). Colony abbreviations as in Table 1. Ecoregions - 1: Kara Sea; 2: Barents Sea; 3: Norwegian Sea; 4: Greenland Sea; 5: Iceland Sea \& Shelf; 6: Faroe Plateau; 7: Central North Atlantic; 8: Celtic-Biscay Shelf; 9: North Sea; 10: West Greenland \& Canada East Arctic; 11: Labrador Sea; 12: Newfoundland \& Labrador Shelf (including the Grand Banks); 13: Hudson Bay Complex; 14: Scotian Shelf; 15: Northeast US Continental Shelf; 16: Mid-Atlantic; 17: Iberian Coastal; 18: Baltic Sea

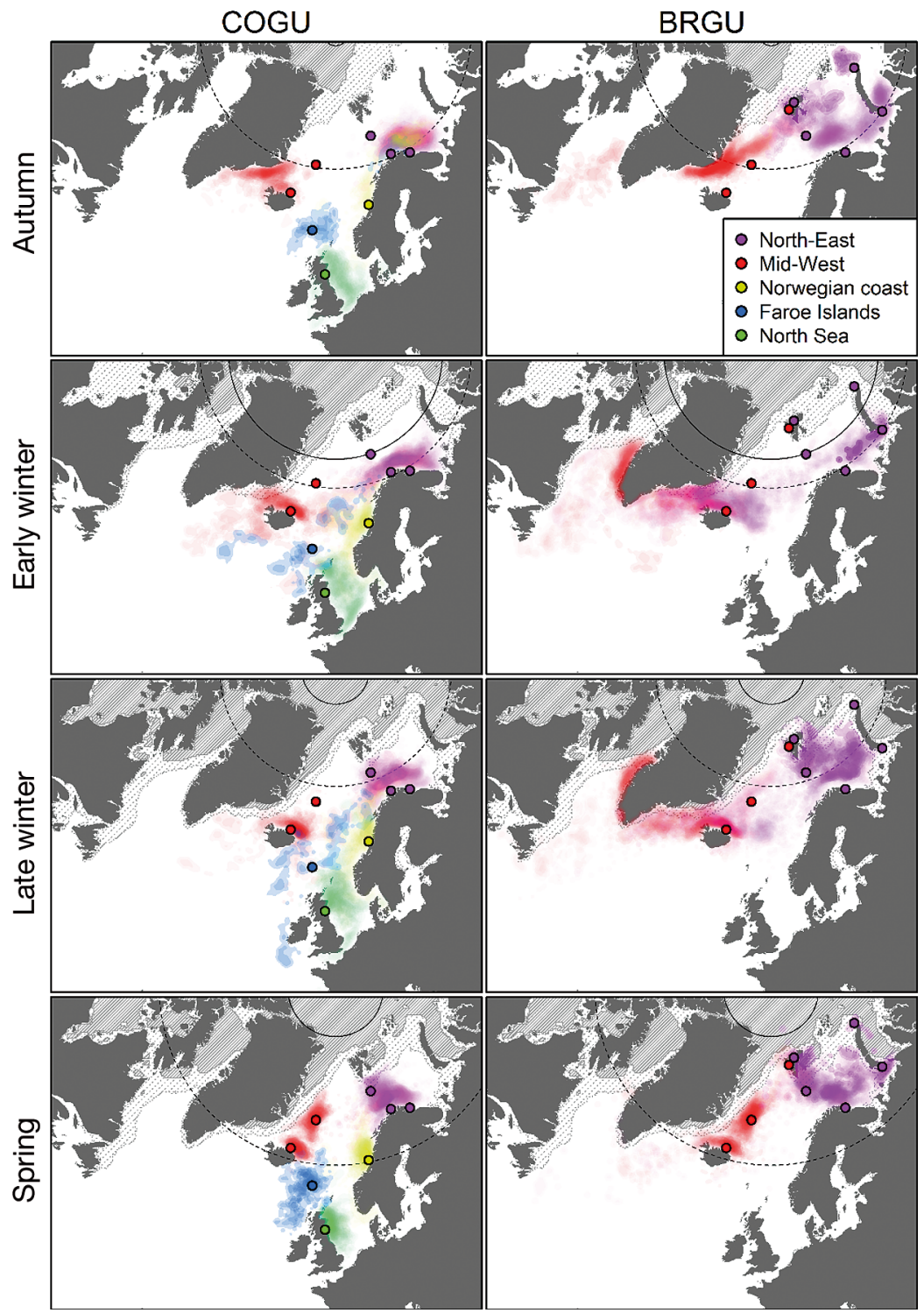

(Fig. 4). In contrast, BRGU populations in the North-East cluster - mainly constrained to the Barents Sea - inhabited distinct environments throughout the non-breeding period. COGU clusters generally occupied cluster-specific environments with most variability displayed for populations in the MidWest cluster. Differential segregation between the 2 sympatrically breeding species in space and sometimes environment experienced was displayed to a variable extent during all seasons, except spring (Figs. 4 \& S1.6) Between-species mixing in the MidWest cluster was more prevalent than in the North-East cluster.

\subsection{Population spread}

The observed strong migratory connectivity in geographic and environmental space was also visible in species and population spread in both species. Compared to COGUs, BRGUs dispersed over a wider area which was characterised by more heterogeneous environments in all seasons (Fig. 5). For none of the breeding populations did individuals ever utilise the entire space or environment occupied by the entire species. However, BRGU populations generally spread

Fig. 2. Seasonal distributions (in polar stereographic projection) for COGUs and BRGUs during autumn, early winter, late winter and spring. Kernel utilisation distributions (UD) show seasonal space use by breeding population as composite of individual UDs scaled to their respective population sample size. High colour intensity indicates use by several populations. Dots: colony locations; dashed and solid large circles: areas where location estimation was affected by or impossible due to polar night or midnight sun, respectively; grey stippled and hatched areas: 15 and $90 \%$ ten yr seasonal median sea ice concentration, respectively. Colours correspond to spatiotemporal clusters identified by network analysis (Fig. 1B) 


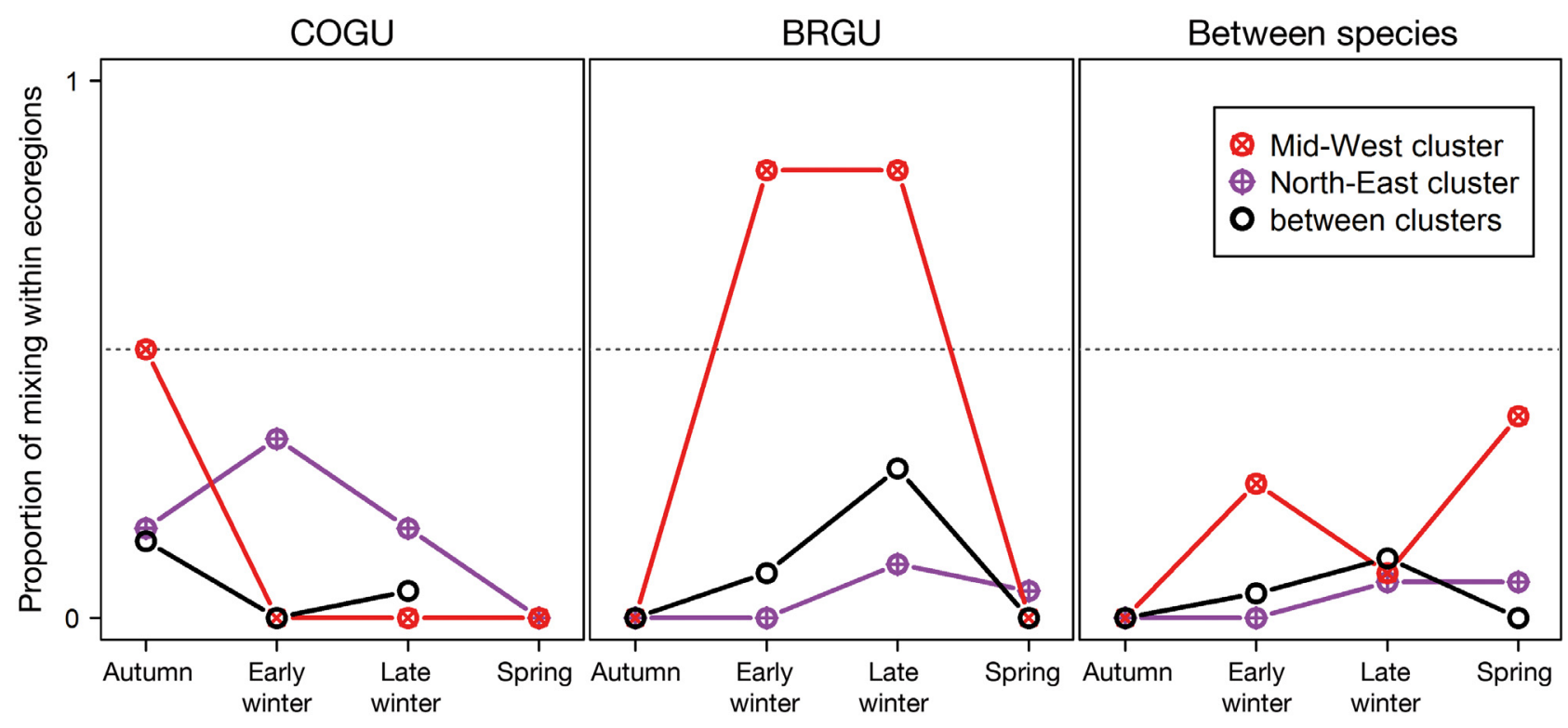

Fig. 3. Overall seasonal proportion of mixing between different populations occupying the same ecoregion and belonging to the same species or different species (Eq. 1). This index ranges from 0 (segregation of different populations in the same ecoregions) to 1 (mixing of different populations in the same ecoregions). Colours denote comparisons within and between identified clusters (detailed in Fig. 1B). No COGU populations belonging to different clusters occupied the same ecoregion during spring (Fig. 1B). Consequently, no proportion of mixing could be estimated during this season. Inter-population mixing could only be calculated for the Mid-West and the North-East clusters, as the other 3 clusters only consist of one population each

out over more space and environments compared to COGU populations (Fig. 5). Both species exhibited more concentrated space use during autumn and spring and spread out more in the winter seasons. This pattern was also apparent at the population level. Finally, neither species utilised its entire annual occupied range in space or the environment during any given season (Fig. 5).

\section{DISCUSSION}

Our analysis of meta-population-level migratory connectivity for the genus Uria revealed that COGUs exhibit strong migratory connectivity - in terms of low inter-population mixing and low population spread - with population space use during the nonbreeding period corresponding to their population trends. Populations of BRGUs - which are generally declining across the entire studied range (Frederiksen et al. 2016, Anker-Nilssen et al. 2017) also show rather strong migratory connectivity and cluster into 2 distinct groups which have not been described previously (Frederiksen et al. 2016). Compared to COGUs, the BRGU meta-population spreads out over a larger area, characterised by more heterogeneous environments (McFarlane Tranquilla et al. 2015), and exhibits more mixing between the study populations, including within ecoregions. In all populations where the 2 species breed sympatrically, they segregate in space and often in environmental use throughout the non-breeding period. Generally, guillemot space use as well as environments occupied in the Northeast Atlantic were found to be speciesand population-specific, with low spatiotemporal variability, similar to the Northwest Atlantic (McFarlane Tranquilla et al. 2013) and the Pacific (Takahashi et al. 2021). This suggests that both species are comprised of space and environmental niche specialist populations. Overall, a strong seasonal pattern in space use and environmental spread was apparent. This pattern was likely driven by life history stages of the annual cycle of the 2 species, such as restricted movement capabilities during the autumn moult (Birkhead \& Taylor 1977, Thompson et al. 1998, Bridge 2004, Elliott \& Gaston 2014) and pre egg-laying colony attendance (Merkel et al. 2019).

The correlation between population trends and identified migration strategy clusters in Uria spp. (shown for COGUs in this study and for BRGUs in Frederiksen et al. 2016) as well as the spatial, and to some extent environmental, isolation between these clusters, indicates that their population trends are linked to their non-breeding distributions (Desprez et al. 2018). Alternatively, population trends might be affected by conditions during the breeding period 


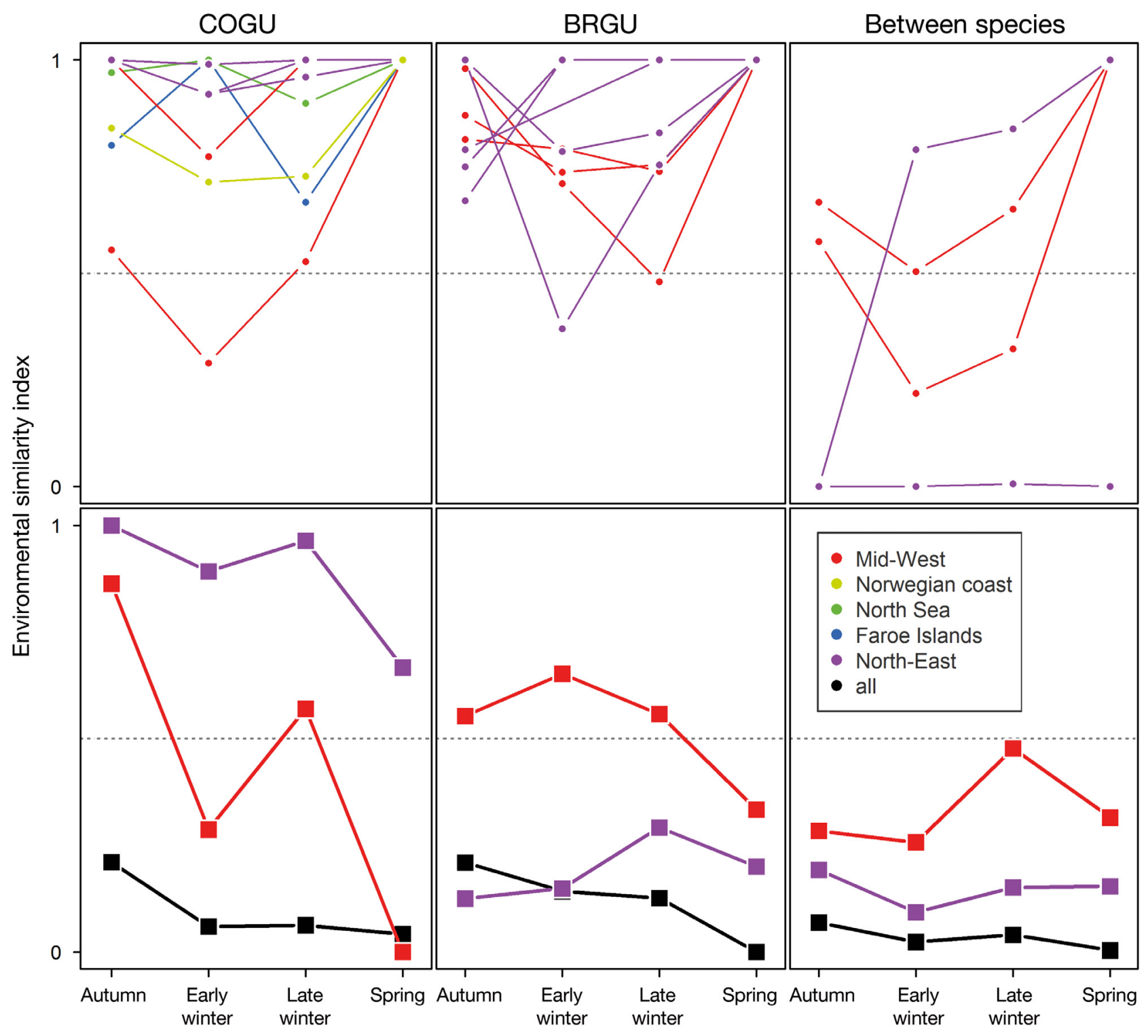

Fig. 4. Environmental similarity index by season within and between species. This index ranges from 0 (all birds occupy distinct environments) to 1 (all birds occupy a similar environment) and quantifies the seasonal mixing of environmental niches occupied within and across populations and clusters (detailed in Fig. 1B). Top panels (with small circles): intra-population estimates (degree of similarity within populations); bottom panels (with bigger squares): comparative environmental similarities within clusters (i.e. inter-population) or for all clusters combined (across all populations, in black)

(through a change in breeding success and propensity). However, this is unlikely due to the large distance between breeding populations (Frederiksen et al. 2016). Intra- and inter-specific competition for food are predicted to play a key role in shaping population- and meta-population-scale migratory strategies (Svanbäck \& Bolnick 2007). Such competition may explain why the studied populations exhibit such strong connectivity and seldom travel towards the Grand Banks and the Labrador shelf during the non-breeding periods. These areas have already been suggested as seabird wintering hotspots (Frederiksen et al. 2012, Montevecchi et al. 2012, Fort et al. 2013a, Fayet et al. 2017), in particular for Canadian and West Greenland guillemot populations (McFarlane Tranquilla et al. 2013, Frederiksen et al. 2016). Guillemots breeding in the Northeast Atlantic may avoid these areas to limit competition for food. Alternatively, the Grand Banks and Labrador shelf may be outside the migratory range for these populations. Due to extremely high flight costs (Elliott et al. 2013), Uria spp. have a theoretical maximum migra- 

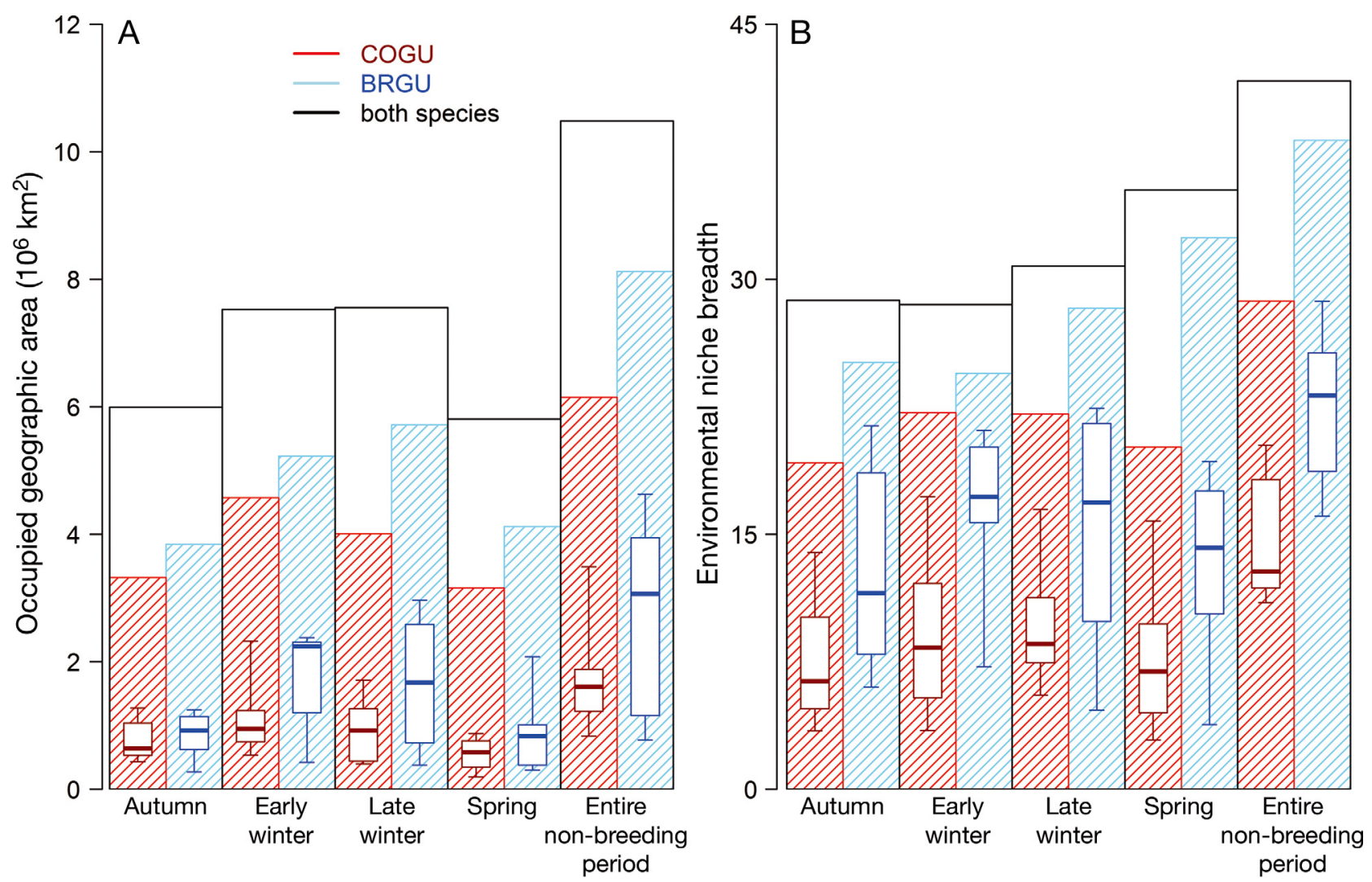

Fig. 5. Size of the (A) occupied geographic and (B) environmental space in each season and both species combined as well as for COGUs and BRGUs. Bar plots denote the size of the entire occupied seasonal space (meta-population spread) while each boxplot displays the range of area occupied by each breeding population. Box plot: $25^{\text {th }}, 50^{\text {th }}$ (median) and $75^{\text {th }}$ percentiles; whiskers: minimum and maximum values

tory range of $\sim 3400 \mathrm{~km}$ from their respective breeding sites (Watanabe 2016). The Grand Banks and Labrador would thus be outside this range for all populations included in this study, except for the Icelandic colonies. Only 10 BRGU annual tracks ( 2\% of all BRGU tracks) and no COGU tracks exceeded the theoretical migration range. These 10 tracks were mainly from individuals utilising the Grand Banks and the Labrador Shelf (range: $3500-4600 \mathrm{~km}$ ). This supports the hypothesis that migration distance is a limiting factor for guillemots.

The relative location of colonies to prevailing surface currents might influence breeding-population-specific migration strategies, especially during autumn when both sexes are flightless and successfully breeding males accompany a flightless chick (Frederiksen et al. 2016). However, we have a poor understanding of the ontogeny of individual migration patterns and the relative roles of genetics (Liedvogel et al. 2011) and social learning therein (Senner et al. 2015, Keith \& Bull 2017, Jesmer et al. 2018). The high population specificity and low diversity of COGU and BRGU migration strategies could be explained by a range of factors. These include (1) culturally acquired knowledge on (Grémillet et al. 2004, Guilford et al. 2011), or the lack of, historically adequate staging areas (Van Moorter et al. 2016, Thorup et al. 2017) during different seasons, (2) high flight costs (Elliott et al. 2013), and connected to it, (3) a morphologically determined maximum migration range (Watanabe 2016) as well as (4) density-dependent competition (Svanbäck \& Bolnick 2007). In order to test these factors, it is essential to combine information about movement patterns of immatures and their parents and to enhance knowledge about potential genetic differences between breeding populations. Merkel et al. (2020) recently showed that adults of both species from multiple colonies exhibit individual consistency in their non-breeding movements over large parts of their distributional range and over multiple years. This suggests potentially less flexibility to rapidly changing environments in the context of global change. However, to what extent individual 
migration patterns are fixed or adaptive to environmental changes over an individual's entire life span needs to be further investigated (Senner et al. 2015) to better assess population level impacts of environmental change (Irons et al. 2008).

Migratory strategies evolved in order to take advantage of seasonal, energetically favourable food resources and avoid unfavourable conditions (Bridge et al. 2016). Different prey species or populations might be targeted by individuals with different strategies. These in turn might be influenced by different environmental conditions and changes in these conditions (Rose 2005, Carscadden et al. 2013, Fossheim et al. 2015, Beaugrand \& Kirby 2018), resulting in migration strategies linked to specific population trends, as recently documented in Atlantic puffins (Fratercula arctica; Fayet et al. 2017), Vermivora warblers (Kramer et al. 2018) and Wood thrushes (Hylocichla mustelina; Taylor \& Stutchbury 2016). Migratory plasticity is predicted to buffer populations against perturbations at local and regional scales (Cresswell 2014, Betini et al. 2015, Gilroy et al. 2016). Here, we demonstrated strong migratory connectivity and often little variability among individual migration strategies across all study populations and both species, suggesting only limited capacity to buffer against local and regional perturbations. We also demonstrated that individuals from the same breeding population, even when occupying different areas, tended to occupy environments with similar abiotic conditions, which may explain their general susceptibility to regional (e.g. sea level pressure; Vader et al. 1990, Mesquita et al. 2015) and large-scale climatic features (e.g. the North Atlantic subpolar gyre; Descamps et al. 2013, Fluhr et al. 2017). Variability in environmental space is implied within the population spread component of migratory connectivity, where larger spread is assumed to be associated with more diverse environments experienced by a population (Gilroy et al. 2016, Finch et al. 2017). However, we showed that variability in geographic area does not necessarily lead to variability in environmental space. Hence, an assessment of environmental variability in addition to migratory connectivity is needed to evaluate population responses to perturbations. In both species, space use was most restricted during autumn and spring, which corresponded to low variability in environmental characteristics. This suggests low capacity to adjust to perturbations during these periods, under the constraints set by the breeding cycle (such as molt of their flight feathers and pre-laying colony attendance; Dias et al. 2011, Desprez et al. 2018).

\section{CONCLUSIONS}

We provide evidence of strong migratory connectivity within and between 2 congeneric seabird species at an ocean basin scale, and highlight the importance of considering not only space use, but also its seasonality and occupied environmental niches. Birds from different populations and species are specialized in both their seasonal space and environmental use, utilising only a fraction of the potential species-wide range. These spatiotemporal dynamics are concordant to population trends. This emphasizes the importance of migratory connectivity and the environmental conditions experienced during the non-breeding period as drivers of population dynamics in migratory species, particularly in the context of global change.

Acknowledgements. Funding for this study was provided by the Norwegian Ministry for Climate and the Environment, the Norwegian Ministry of Foreign Affairs and the Norwegian Oil and Gas Association through the SEATRACK project (www.seapop.no/en/seatrack) as well as from the Research Council of Norway (project 216547), TOTAL E\&P Norway and the TOTAL Foundation and the UK Natural Environment Research Council's National Capability. We thank Børge Moe, Hálfdán Helgi Helgason and Vegard Sandøy Bråthen for the logistical support within SEA TRACK. This work would not have been possible without the combined effort and long term engagement of many researchers, as well as numerous field assistants all across the Northeast Atlantic.

\section{LITERATURE CITED}

Amante C, Eakins BW (2009) ETOPO1 1 arc-minute global relief model: procedures, data sources and analysis. NOAA Tech Memo NESDIS NGDC-24

*Ambrosini R, Møller AP, Saino N (2009) A quantitative measure of migratory connectivity. J Theor Biol 257: 203-211

Anker-Nilssen T, Strøm H, Barrett RT, Sivertsen K (2017) Sjøfugl i Norge 2017. In: Anker-Nilssen T (ed) Resultater fra SEAPOP programmet. SEAPOP, Trondheim

Bauer S, Lisovski S, Hahn S (2016) Timing is crucial for consequences of migratory connectivity. Oikos 125:605-612

*Beaugrand G, Kirby RR (2018) How do marine pelagic species respond to climate change? Theories and observations. Annu Rev Mar Sci 10:169-197

Benowitz-Fredericks ZM, Kitaysky AS (2005) Benefits and costs of rapid growth in common murre chicks Uria aalge. J Avian Biol 36:287-294

Betini GS, Fitzpatrick MJ, Norris DR (2015) Experimental evidence for the effect of habitat loss on the dynamics of migratory networks. Ecol Lett 18:526-534

Birkhead TR, Taylor AM (1977) Moult of the guillemot Uria aalge. Ibis 119:80-85

Borcard D, Gillet F, Legendre P (2018) Numerical ecology with R. Springer, New York, NY 
Bridge ES (2004) The effects of intense wing molt on diving in alcids and potential influences on the evolution of molt patterns. J Exp Biol 207:3003-3014

Bridge ES, Ross JD, Contina AJ, Kelly JF (2016) Do moltmigrant songbirds optimize migration routes based on primary productivity? Behav Ecol 27:784-792

Broennimann O, Fitzpatrick MC, Pearman PB, Petitpierre B and others (2012) Measuring ecological niche overlap from occurrence and spatial environmental data. Glob Ecol Biogeogr 21:481-497

Calenge C (2006) The package 'adehabitat' for the R software: a tool for the analysis of space and habitat use by animals. Ecol Modell 197:516-519

* Carscadden JE, Gjøsæter H, Vilhjálmsson H (2013) A comparison of recent changes in distribution of capelin (Mallotus villosus) in the Barents Sea, around Iceland and in the Northwest Atlantic. Prog Oceanogr 114:64-83

* Clauset A, Newman MEJ, Moore C (2004) Finding community structure in very large networks. Phys Rev E 70: 066111

Cohen EB, Hostetler JA, Hallworth MT, Rushing CS, Sillett TS, Marra PP (2018) Quantifying the strength of migratory connectivity. Methods Ecol Evol 9:513-524

Cramp S (1985) The Birds of the Western Palearctic, Vol 4. Oxford University Press, Oxford

Cresswell W (2014) Migratory connectivity of PalaearcticAfrican migratory birds and their responses to environmental change: the serial residency hypothesis. Ibis 156 : 493-510

Csárdi G, Nepusz T (2006) The igraph software package for complex network research. InterJ Complex Syst 1695: $1-9$

Davies KF, Margules CR, Lawrence JF (2004) A synergistic effect puts rare, specialized species at greater risk of extinction. Ecology 85:265-271

Descamps S, Strøm H, Steen H (2013) Decline of an Arctic top predator: synchrony in colony size fluctuations, risk of extinction and the subpolar gyre. Oecologia 173: $1271-1282$

* Desprez M, Jenouvrier S, Barbraud C, Delord K, Weimerskirch H (2018) Linking oceanographic conditions, migratory schedules and foraging behaviour during the non-breeding season to reproductive performance in a long-lived seabird. Funct Ecol 32:2040-2053

Dias MP, Granadeiro JP, Phillips RA, Alonso H, Catry P (2011) Breaking the routine: individual Cory's shearwaters shift winter destinations between hemispheres and across ocean basins. Proc R Soc B 278:1786-1793

Elliott KH, Gaston AJ (2014) Dive behavior and daily energy expenditure in thick-billed murres Uria lomvia after leaving the breeding colony. Mar Ornithol 42:183-189

Elliott KH, Ricklefs RE, Gaston AJ, Hatch SA, Speakman JR, Davoren GK (2013) High flight costs, but low dive costs, in auks support the biomechanical hypothesis for flightlessness in penguins. Proc Natl Acad Sci USA 110: 9380-9384

Elliott KH, Linnebjerg JF, Burke C, Gaston AJ, Mosbech A, Frederiksen M, Merkel F (2017) Variation in growth drives the duration of parental care: a test of Ydenberg's Model. Am Nat 189:526-538

Eyres A, Böhning-Gaese K, Fritz SA (2017) Quantification of climatic niches in birds: adding the temporal dimension. J Avian Biol 48:1517-1531

Fauchald P, Anker-Nilssen T, Barrett RT, Bustnes JO and others (2015) The status and trends of seabirds breeding in Norway and Svalbard. In: Fauchald P (ed) NINA Rapport, Book 1151. NINA, Trondheim, p1-84

F Fayet AL, Freeman R, Anker-Nilssen T, Diamond A and others (2017) Ocean-wide drivers of migration strategies and their influence on population breeding performance in a declining seabird. Curr Biol 27:3871-3878

Fieberg J, Kochanny CO (2005) Quantifying home-range overlap: the importance of the utilization distribution. J Wildl Manag 69:1346-1359

* Finch T, Butler SJ, Franco AMA, Cresswell W (2017) Low migratory connectivity is common in long-distance migrant birds. J Anim Ecol 86:662-673

Fluhr J, Strøm H, Pradel R, Duriez O, Beaugrand G, Descamps $S$ (2017) Weakening of the subpolar gyre as a key driver of North Atlantic seabird demography: a case study with Brünnich's guillemots in Svalbard. Mar Ecol Prog Ser 563:1-11

Fort J, Porter WP, Grémillet D (2009) Thermodynamic modelling predicts energetic bottleneck for seabirds wintering in the northwest Atlantic. J Exp Biol 212:2483-2490

Fort J, Moe B, Strøm H, Grémillet D and others (2013a) Multicolony tracking reveals potential threats to little auks wintering in the North Atlantic from marine pollution and shrinking sea ice cover. Divers Distrib 19:1322-1332

Fort J, Steen H, Strøm H, Tremblay Y and others (2013b) Energetic consequences of contrasting winter migratory strategies in a sympatric Arctic seabird duet. J Avian Biol 44:255-262

* Fossheim M, Primicerio R, Johannesen E, Ingvaldsen RB, Aschan MM, Dolgov AV (2015) Recent warming leads to a rapid borealization of fish communities in the Arctic. Nat Clim Chang 5:673-677

Frederiksen M (2010) Seabirds in the North East Atlantic. Summary of status, trends and anthropogenic impact. In: Action plan for seabirds in Western-Nordic areas: report from a workshop in Malmö, Sweden, 4-5 May 2010. Nordic Council of Ministers, Copenhagen, p 21-24

*Frederiksen M, Moe B, Daunt F, Phillips RA and others (2012) Multicolony tracking reveals the winter distribution of a pelagic seabird on an ocean basin scale. Divers Distrib 18:530-542

Frederiksen M, Descamps S, Erikstad KE, Gaston AJ and others (2016) Migration and wintering of a declining seabird, the thick-billed murre Uria lomvia, on an ocean basin scale: conservation implications. Biol Conserv 200: $26-35$

Garðarsson A, Guðmundsson GA, Lilliendahl K (2019) The numbers of large auks on the cliffs of Iceland in 2006-2008. Bliki 33:35-46

Gaston AJ, Jones IL (1998) Bird families of the world. The Auks: Alcidae. Oxford University Press, Oxford

Gaston AJ, Powell A (2003) Synchronous fluctuations of thick-billed murre (Uria lomvia) colonies in the Eastern Canadian Arctic suggest population regulation in winter. Auk 120:362-370

Gilroy JJ, Gill JA, Butchart SHM, Jones VR, Franco AMA (2016) Migratory diversity predicts population declines in birds. Ecol Lett 19:308-317

* Godley BJ, Barbosa C, Bruford M, Broderick AC and others (2010) Unravelling migratory connectivity in marine turtles using multiple methods. J Appl Ecol 47:769-778

Gómez C, Tenorio EA, Montoya P, Cadena CD (2016) Nichetracking migrants and niche-switching residents: evolution of climatic niches in New World warblers (Parulidae). Proc R Soc B 283:20152458 
Grémillet D, Dell'Omo G, Ryan PG, Peters G, Ropert-Coudert Y, Weeks SJ (2004) Offshore diplomacy, or how seabirds mitigate intra-specific competition: a case study based on GPS tracking of Cape gannets from neighbouring colonies. Mar Ecol Prog Ser 268:265-279

Guilford T, Freeman R, Boyle D, Dean B, Kirk H, Phillips R, Perrins C (2011) A dispersive migration in the Atlantic puffin and its implications for migratory navigation. PLOS ONE 6:e21336

Hahn S, Amrhein V, Zehtindijev P, Liechti F (2013) Strong migratory connectivity and seasonally shifting isotopic niches in geographically separated populations of a long-distance migrating songbird. Oecologia 173: 1217-1225

Harris MP, Wanless S (1990) Breeding status and sex of common murres (Uria aalge) at a colony in autumn. Auk 107: 603-605

炎Irons DB, Anker-Nilssen T, Gaston AJ, Byrd GV and others (2008) Fluctuations in circumpolar seabird populations linked to climate oscillations. Glob Change Biol 14: 1455-1463

Jakobsson M, Mayer L, Coakley B, Dowdeswell JA and others (2012) The international bathymetric chart of the Arctic Ocean (IBCAO) version 3.0. Geophys Res Lett 39: L12609

Jesmer BR, Merkle JA, Goheen JR, Aikens EO and others (2018) Is ungulate migration culturally transmitted? Evidence of social learning from translocated animals. Science 361:1023-1025

JNCC (Joint Nature Conservation Committee) (2016) Seabird population trends and causes of change: 1986-2015 Report. Joint Nature Conservation Committee, Peterborough

Keith SA, Bull JW (2017) Animal culture impacts species' capacity to realise climate-driven range shifts. Ecography 40:296-304

Kramer GR, Andersen DE, Buehler DA, Wood PB and others (2018) Population trends in Vermivora warblers are linked to strong migratory connectivity. Proc Natl Acad Sci USA 115:E3192-E3200

La Sorte FA, Fink D, Johnston A (2018) Seasonal associations with novel climates for North American migratory bird populations. Ecol Lett 21:845-856

* Lavergne S, Evans MEK, Burfield IJ, Jiguet F, Thuiller W (2013) Are species' responses to global change predicted by past niche evolution? Philos Trans R Soc B 368: 20120091

Liedvogel M, Åkesson S, Bensch S (2011) The genetics of migration on the move. Trends Ecol Evol 26:561-569

* McFarlane Tranquilla LA, Montevecchi WA, Hedd A, Fifield DA and others (2013) Multiple-colony winter habitat use by murres Uria spp. in the Northwest Atlantic Ocean: implications for marine risk assessment. Mar Ecol Prog Ser 472:287-303

* McFarlane Tranquilla L, Montevecchi WA, Hedd A, Regular PM, Robertson GJ, Fifield DA, Devillers R (2015) Ecological segregation among thick-billed murres (Uria lomvia) and common murres (Uria aalge) in the Northwest Atlantic persists through the nonbreeding season. Can J Zool 93:447-460

Merkel B, Phillips RA, Descamps S, Yoccoz NG, Moe B, Strøm H (2016) A probabilistic algorithm to process geolocation data. Mov Ecol 4:26

Merkel B, Descamps S, Yoccoz NG, Danielsen J and others (2019) Earlier colony arrival but no trend in hatching tim- ing in two congeneric seabirds (Uria spp.) across the North Atlantic. Biol Lett 15:20190634

Merkel B, Descamps S, Yoccoz NG, Grémillet D and others (2021) Individual migration strategy fidelity but no habitat specialization in two congeneric seabirds. J Biogeogr 48:263-275

Mesquita MdS, Erikstad KE, Sandvik H, Barrett RT and others (2015) There is more to climate than the North Atlantic Oscillation: a new perspective from climate dynamics to explain the variability in population growth rates of a long-lived seabird. Front Ecol Evol 3:43

*Montevecchi WA, Hedd A, McFarlane Tranquilla L, Fifield DA and others (2012) Tracking seabirds to identify ecologically important and high risk marine areas in the western North Atlantic. Biol Conserv 156:62-71

* Peters W, Hebblewhite M, Mysterud A, Spitz D and others (2017) Migration in geographic and ecological space by a large herbivore. Ecol Monogr 87:297-320

R Development Core Team (2017) R: a language and environment for statistical computing. R Foundation for Statistical Computing, Vienna

Robinson RA, Crick HQP, Learmonth JA, Maclean IMD and others (2009) Travelling through a warming world: climate change and migratory species. Endang Species Res 7:87-99

Rooker JR, Secor DH, De Metrio G, Schloesser R, Block BA, Neilson JD (2008) Natal homing and connectivity in Atlantic bluefin tuna populations. Science 322: 742-744

Rose GA (2005) On distributional responses of North Atlantic fish to climate change. ICES J Mar Sci 62: 1360-1374

Russell DJF, McConnell B, Thompson D, Duck C and others (2013) Uncovering the links between foraging and breeding regions in a highly mobile mammal. J Appl Ecol 50:499-509

Senner NR, Conklin JR, Piersma T (2015) An ontogenetic perspective on individual differences. Proc R Soc B 282: 20151050

* Skjoldal HR, Mundy P (2013) Large marine ecosystems (LMEs) of the Arctic area-revision of the Arctic LME map. Protection of the Arctic Marine Environment, Akureyri

* Soberón J (2007) Grinnellian and Eltonian niches and geographic distributions of species. Ecol Lett 10:1115-1123

* Soberón J, Nakamura M (2009) Niches and distributional areas: concepts, methods, and assumptions. Proc Natl Acad Sci USA 106:19644-19650

* Svanbäck R, Bolnick DI (2007) Intraspecific competition drives increased resource use diversity within a natural population. Proc R Soc B 274:839-844

Takahashi A, Thiebot JB, Will A, Tsukamoto S, Merkel B, Kitaysky A (2021) Breeding together, wintering an ocean apart: foraging ecology of the northern Bering Sea thick-billed and common murres in years of contrasting sea-ice conditions. Polar Sci 27:100552

Taylor CM, Norris DR (2010) Population dynamics in migratory networks. Theor Ecol 3:65-73

Taylor CM, Stutchbury BJM (2016) Effects of breeding versus winter habitat loss and fragmentation on the population dynamics of a migratory songbird. Ecol Appl 26: 424-437

* Thompson CW, Wilson ML, Melvin EF, Pierce DJ (1998) An unusual sequence of flight-feather molt in common murres and its evolutionary implications. Auk 115:653-669 
Thorup K, Tøttrup AP, Willemoes M, Klaassen RHG and others (2017) Resource tracking within and across continents in long-distance bird migrants. Sci Adv 3: $\mathrm{e} 1601360$

Thuiller W, Lavorel S, Araújo MB (2005) Niche properties and geographical extent as predictors of species sensitivity to climate change. Glob Ecol Biogeogr 14:347-357

Vader W, Barrett R, Erikstad K, Strann K (1990) Differential responses of common and thick-billed murres to a crash in the capelin stock in the southern Barents Sea. Stud Avian Biol 14:175-180

Van Moorter B, Rolandsen CM, Basille M, Gaillard JM

Editorial responsibility: Stephen C. Votier (Guest Editor), Cornwall, UK

Reviewed by: S. Lisovski and 2 anonymous referees
(2016) Movement is the glue connecting home ranges and habitat selection. J Anim Ecol 85:21-31

*Warren DL, Glor RE, Turelli M, Funk D (2008) Environmental niche equivalency versus conservatism: quantitative approaches to niche evolution. Evolution 62:2868-2883

* Watanabe YY (2016) Flight mode affects allometry of migration range in birds. Ecol Lett 19:907-914

*Webster MS, Marra PP, Haig SM, Bensch S, Holmes RT (2002) Links between worlds: unraveling migratory connectivity. Trends Ecol Evol 17:76-83

* Wilcove DS, Wikelski M (2008) Going, going, gone: Is animal migration disappearing? PLOS Biol 6:e188

Submitted: July 14, 2020

Accepted: November 11, 2020

Proofs received from author(s): February 15, 2021 